Artigo

Jean-Luc Metzger ${ }^{1}$

\title{
Mudança permanente: fonte de penosidade no trabalho?*
}

\author{
Perpetual change: source of penibility at work?
}

\author{
1 Pesquisador associado do Centre \\ National dês Arts et Métiers - \\ Laboratoire Interdisciplinaire pour la \\ Sociologie Economique (CNAM-LISE), \\ Paris, França. \\ Contato: \\ 41, rue de la Fontaine Grelot; Bâtiment \\ 6; 92340 Bourg-la-Reine, France \\ Email: \\ jeanluc.metzger@orange-ftgroup.com \\ *Tradução: Selma Venco \\ Revisão técnica da tradução: José Marçal \\ Jackson Filho \\ Artigo parcialmente baseado na \\ tese para l'Habilitation à Diriger des \\ Recherches (HDR) intitulada La volonté \\ de changer: I'instituition du travail au risque \\ du changement technico-organisationnel \\ permanent, apresentada à l'Université \\ d'Evry Val d'Essonne, em 2007.
}

\section{Resumo}

Este artigo se propõe a examinar as possíveis condições para a melhoria duradoura da saúde psíquica dos trabalhadores. Para fazê-lo, após ter sintetizado as principais causas imediatas dos problemas psicossociais, recolocamo-los no contexto contemporâneo caracterizado pela renovação incessante dos dispositivos técnicos e de gestão. Assim, compreender os fenômenos dos problemas psicossociais no trabalho implica em se interessar pelos efeitos da mudança permanente. Precisamente, para considerarmos, de forma geral, estes efeitos sobre a saúde, elaboramos uma grade de análise a partir da herança da sociologia do trabalho e da noção de trabalho instituição (proposta por Lallement). Esta grade de análise é, em seguida, utilizada em situações empíricas variadas (hospitais, universidades, empresas multinacionais) para demonstrarmos que a mudança permanente engendra uma polarização dos indivíduos. Certos trabalhadores perdem seu vínculo com o trabalho e assim iniciam um processo de degradação de sua saúde, enquanto outros tiram proveito do movimento e permanecem em boa saúde. Enfim, a mudança perpétua é explicada como resultado de dinâmicas próprias ao campo da gestão e de uma postura reificante específica da abordagem racionalizadora. Assim, a fim de melhorar de forma duradoura a saúde psíquica no trabalho, é necessário intervir no coração das relações sociais.

Palavras-chave: mudança permanente; racionalização; gestão; reificação; problemas psicossociais.

\begin{abstract}
The purpose of this article is to examine possible circumstances for a long lasting improvement of workers' psychological health. After having synthesized the main immediate causes of psychosocial problems, those problems were placed in the contemporary context which is characterized by the incessant renewal of technical and managerial apparatus. To understand the phenomena of psychosocial problems at work one has to be aware of the effects of perpetual change. To analyze these effects on workers' health, an analysis grid is presented, which was built based on the heritage of sociology of work and the notion of work institution (proposed by Lallement). This analysis grid is then applied in several empirical situations (hospitals, universities, multinational companies) to demonstrate that permanent changes lead to a polarization of individuals. Some workers loose their connection to work and, as a consequence, develop a process of degradation of their health, while others take advantage of the movement and remain in good health. Finally, perpetual change is explained as a result of typical dynamics of the management field and of a reification posture which is emblematic to the rationalizing approach. Therefore, it is necessary to intervene in the core of social relations to be able to improve workers' psychological health in a long lasting way.
\end{abstract}

Keywords: perpetual change; racionalization; management; reification; psychosocial problems. 


\section{Saúde e trabalho: a importância da mudança técnico-gerencial}

Dispomos hoje de um número significativo de estudos que se interessam pelos efeitos da organização do trabalho sobre a saúde. Para apreciar a importância do fenômeno, pode-se colocar em primeiro lugar dados quantitativos. Neste sentido, Vogel (2009, p. 111) lembra que, "a cada ano, cerca de 160.000 pessoas morrem devido a acidentes de trabalho ou a doenças causadas pelo trabalho na Europa dos Vinte e Sete". Mais precisamente, se os problemas ligados aos ambientes de trabalho perigosos (poeiras, amianto, produtos químicos tóxicos, ruído, trabalho realizado em altura, dentre outros) permanecem estáveis, há uma década constata-se o crescimento dos riscos ligados à organização do trabalho.

O maior problema constitui-se pela intensificação do trabalho (ritmo de trabalho mais elevado, prazos muito restritos). Ela se amplia desde 1991 na Europa e se acompanha da pressão exercida diretamente sobre os trabalhadores em função das exigências do mercado (DEBOUT et al., 2009). Pois, há mais de quinze anos, assiste-se a uma racionalização do trabalho no setor terciário, mais comumente em tudo que diz respeito a serviços de relacionamento com usuários/clientes, como no caso das centrais de atendimento, dos serviços de alimentação do tipo fast food, dos hospitais, inclusive dos serviços públicos e de entidades associativas. A mais evidente manifestação deste crescimento da penosidade $^{2}$ reside na degradação simultânea dos equilíbrios psíquicos e físicos em um número crescente de trabalhadores. Isto se traduz em uma verdadeira "epidemia" de problemas musculoesqueléticos e, ao mesmo tempo, em uma série de sintomas percebidos como estresse e distúrbios psicossociais (DPS).

Certamente, a nova "penosidade" do trabalho parece concernir inicialmente às dimensões psicológicas e se manifesta por um aumento da fadiga, do esgotamento até o burnout -, pelo agravamento de alterações do sono, o aparecimento de doenças psíquicas, como a depressão e o desenvolvimento de distúrbios do comportamento, às vezes chegando à violência, assim como o recrudesci- mento de diferentes formas de vício (álcool, medicamento, dentre outras). Nos casos mais graves, a acumulação de fontes de penosidade e a manutenção de condições de isolamento conduzem os trabalhadores, incluindo-se os quadros, ${ }^{3}$ ao suicídio. Além disso, estes distúrbios, por sua vez, podem ter repercussões sobre o plano físico e resultar em doenças cardiovasculares, distúrbios osteomusculares relacionados ao trabalho (LER/DORT), dentre outros. Ora, mesmo na ausência de gestos repetitivos, a intensificação dos ritmos de trabalho, o aumento das exigências (redução das margens de manobra) e a perda do sentido do trabalho são também fatores que explicam o aumento de LER/DORT (DANIELLOU; ESCRIVA, 2008). Resumindo em uma fórmula, pode-se dizer que, ceteris paribus, quanto menos margem de manobra e trabalho coletivo existirem, mais crescerá a penosidade, degradando simultaneamente as condições de saúde psíquica e física dos trabalhadores.

É o que confirma, por exemplo, Valeyre (2007), que compara os riscos e os danos à saúde no trabalho segundo formas de organização do trabalho. Seu estudo permite destacar o quanto as escolhas organizacionais têm impactos diversificados sobre a saúde ou, dito de outra forma, o quanto certas organizações podem ser mais deletérias que outras. Em particular, as condições de trabalho e a saúde no trabalho são frequentemente piores nas organizações chamadas de produção enxuta (just-in-time, melhoria contínua de produção, produção puxada pelo mercado) que nas organizações tayloristas. Se os mais atingidos são os trabalhadores de baixa qualificação e os precários (LUNDBERG et al., 2007), os quadros são igualmente afetados, especialmente porque são submetidos a normas de qualidade mensuráveis (DAUBAS-LETOURNEUX; THÉBAUD-MONY, 2002).

No cerne do crescimento dos DPS e de suas incidências sobre a saúde física dos trabalhadores, encontram-se, portanto, as novas formas de organização do trabalho (ASKENAZY et al., 2006), as quais agem sobre a saúde de forma indireta. Pressionados para assumirem só a responsabilidade de seu trabalho (quantitativamente e qualitativamente) e sem poder contar com as solidariedades profissionais, os trabalhadores interiorizam as injunções gerenciais de serem "os respon-

\footnotetext{
${ }^{2}$ N.T.: o autor emprega no original a palavra penibilité aqui traduzida por penosidade, embora seu emprego no Brasil seja, de modo geral, menos abrangente. Penibilité é, de um lado, um objeto de pesquisa atual das ciências sociais na França e considerado um conceito em construção, que procura responder à crescente demanda social apresentada por diversas categoriais de trabalhadores devido à degradação de suas condições de trabalho. Por outro lado, a caracterização da penibilité é utilizada pelos sindicatos na negociação social junto às empresas e ao poder público. Considera-se que no Brasil, a categoria penosidade porta frequentemente um caráter objetivo (e, portanto, mensurável), especialmente no campo do direito do trabalho. Ressalte-se que o estudo da penibilité considera também a dimensão subjetiva, a exemplo do analisado por Leny Sato (As implicações do conhecimento prático para a vigilância em saúde do trabalhador. Cad. Saúde Pública, v. 12, n. 4, p. 489-495, 1996), ao ponderar que a compreensão da literatura sobre o tema é estrita à vinculação ao trabalho que requer esforços físicos demasiados, realizados em alto mar, nas alturas ou a céu aberto. Contudo, pela perspectiva do trabalhador, "o que nucleia o conceito, ou seja, o cerne do problema, é o controle, que remete justamente à relação dos trabalhadores com os contextos de trabalho, não se reduzindo a penosidade apenas à presença desses problemas e sim à condição de sujeito na relação de trabalho, onde o incômodo, o sofrimento e o esforço estão presentes. Em outras palavras, neste caso, para o trabalhador, o problema não é o que se denomina de "risco", mas a relação mantida com o trabalho e suas condições, possibilitada pelo contexto organizacional" (SATO, 1996, p. 492).
}

${ }^{3}$ N. T.: No francês, o autor empregou o termo cadres, que optamos por traduzir por quadros. Cadre corresponde ao chamado trabalhador de colarinho branco (em inglês, white collar worker), ou seja, todos os empregados da empresa que não são operários (trabalhador de colarinho azul ou, em ingês, blue collor worker). No Brasil, algumas traduções utilizam a palavra executivo. Todavia, os executivos são apenas parte dos cadres. 
sáveis”. “Tomam para si”, sentem-se responsáveis por seus fracassos (culpabilidade), ainda que devam realizar tarefas "impossíveis" (objetivos irreais, ausência de formação adaptada, impossibilidade de testar) ou executar atividades cujos procedimentos são inadequados (ferramentas ou procedimentos incompatíveis, trabalho coletivamente realizado, mas individualmente avaliado, interrupções frequentes) ou, ainda, efetuar tarefas inúteis (perda do sentido).

Estes fenômenos são muito preocupantes, pois, de um lado, não são reversíveis, ou seja, não é suficiente mudar de posto de trabalho para que os efeitos cessem (POMMIER et al., 2006) e, por outro lado, eles se traduzem pelo desgaste dos trabalhadores que têm mais de 50 anos (DEBRAND; LENGAGNE, 2007). Estes últimos manifestam mais DPS se estão (ou têm sido há muito tempo) submetidos a fortes exigências de tempo, dispõem de frágeis margens de autonomia e recebem formas de retribuição insuficientes (MOLINIÉ, 2006). Ora, em inúmeros países, os governantes editam leis obrigando os trabalhadores a permanecerem no emprego até 65 anos (BOSCH; SCHIEF, 2006). É urgente, portanto, encontrar formas alternativas de organização do trabalho, que, devido a sua incidência positiva sobre a saúde, ao longo da vida profissional, limitaria o desgaste.

Todavia, esta ambição se choca, para nós, com uma das características estruturais das organizações contemporâneas: o processo de transformação incessante de todas as dimensões do trabalho (METZGER, 2007b). Com efeito, não somente a organização do trabalho e do tempo de trabalho evoluiu em direção à intensificação e à precarização das formas de emprego, mas também as características desta intensificação e desta precarização (regras, princípios, ferramentas, localização, responsáveis/gerentes, colegas) mudam frequentemente, o que contribui para desestabilizar, perder o interesse, cansar, desencorajar, a cada ocorrência, uma parcela dos trabalhadores. Isso torna, finalmente, muito difíceis, até mesmo impossíveis, as tentativas para melhorar de forma duradoura a saúde no trabalho.

Prolongando estas reflexões, propomo-nos a mostrar que a causa na origem desta degradação substancial do atual estado de saúde dos trabalhadores e, ao final das contas, em sua decrepitude reside menos em uma forma particular de organização do que no emprego massivo de dispositivos de gestão cuja característica maior é produzir a mudança permanente. Nesta perspectiva, indicaremos, em um primeiro momento, em quê os universos do trabalho podem hoje, mais do que ontem, ser caracterizados pela permanência de seus desacordos (I). Depois, elaboraremos um modelo para analisar os efeitos na saúde desta mudança permanente (II). Tal exercício compreenderá três momentos: inicialmente, extrair os principais aportes da sociologia do trabalho em matéria de estudo da mudança (II-a); depois, articular estes aos da sociologia econômica por meio da noção de instituição (II-b); enfim, construir uma grade de análise detalhada (II-c). Em um terceiro momento, mobilizaremos esta grade para contemplar as articula- ções complexas entre saúde no trabalho e renovação técnico-gerencial (III). Identificaremos, assim, os efeitos de polarização da mudança permanente. No quarto momento (IV), propor-no-emos a considerar a existência desta mudança permanente por meio de duas dinâmicas: a primeira, própria ao fenômeno gerencial em si (IV-a); e a segunda, relativa ao pensamento racionalizador de uma forma geral (IV-b). Disporemos, assim, ao final deste percurso, de uma visão do conjunto dos meios de ação que permitem melhorar de forma duradoura a saúde dos trabalhadores.

\section{I) Trabalhar é procurar se adaptar ao imperativo da mudança permanente}

\section{Esferas profissionais e vontade de mudar}

O que caracteriza, atualmente, as esferas profissionais reside menos no uso de certos dispositivos técnicos ou de gestão (MAUGERI, 2006) do que na pressão para renovar incessantemente todas as dimensões do trabalho. Certamente, estas injunções para se adaptar incessantemente não são novas: elas são, de certo modo, consubstanciais à racionalização dos modos de produção industrial (FRIEDMANN, 1964; NAVILLE, 1963). Contudo, os mundos sociais do trabalho, desde o final dos anos 1970, conhecem uma aceleração do ritmo destas injunções para as mudanças.

Esta aceleração é, ela mesma, resultado de uma sucessão de decisões tomadas pelas elites políticas e econômicas de muitos países: globalização dos mercados financeiros e das bolsas de valores, desregulamentação e re-regulação parcial dos setores bancários, abertura dos mercados de produtos e depois de serviços, privatização das esferas públicas e transformação do modo de ação do Estado, concorrência acirrada em certos setores seguida de concentração em escala internacional, dependência crescente de investimentos voláteis, dentre outras (MARTIN; METZGER; PIERRE, 2003).

Todos estes fenômenos, cuja dinâmica está inacabada, resultam de vontades acumuladas em várias décadas, avançando apesar das reticências mais ou menos localizadas e dos conflitos mais ou menos longos. Estas decisões, tomadas em níveis cada vez mais internacionais, porque não globais, se traduzem pela influência crescente dos representantes dos acionistas procedendo, para obter rendimentos financeiros suficientes, a compras ou a vendas de empresas, incitando as equipes dirigentes (frequentemente integradas aos acionistas) a operar fusões, reestruturações e reforçando, assim, sua propensão a praticar mudanças de estratégia e das modalidades de gestão.

Para implementar estas diferentes reconfigurações, as direções e suas equipes de especialistas introduzem regras e ferramentas de gestão, frequentemente renovadas, estejam elas ou não inseridas nas tecnologias de informação e de comunicação. Trata-se, então, de racionalizar tanto os processos produtivos (organização, con- 
trole e avaliação da produção, em quantidade e em "qualidade”), quanto as diferentes dimensões da gestão de recursos humanos (recrutamento, avaliação individual, salários, tempo de trabalho, formação, dentre outras), assim como a elaboração dos saberes e do saber-fazer, sem deixar de lado as relações entre os trabalhadores. Estas injunções concernem, principalmente, às empresas comerciais, mas as organizações associativas e públicas não fogem a esta dinâmica. A evidência destas práticas se mede tanto nos estudos centrados em uma empresa (LALLEMENT; METZGER, 2009), quanto nos estudos quantitativos que consideram o conjunto dos trabalhadores (GOLLAC; GUYOT; VOLKOFF, 2008; VALEYRE, 2007). Acrescentamos que este reformismo está a serviço da competitividade das economias nacionais, comparadas por meio dos indicadores do World Competitiveness Index (GAULEJAC, 2005) .

\section{Articular evoluçóes dos mundos sociais e mudança técnico-gerencial}

É frequente considerar que uma causa essencial da mudança permanente reside na utilização massiva, ou na injunção de utilizar massivamente, as tecnologias de informação e de comunicação (TICs). É necessário, entretanto, dispensar certo tempo para precisar que estas tecnologias não se difundem sozinhas, como sob o efeito de um mecanismo automático, mas graças ao engajamento de especialistas das engenharias e das ciências sociais, em interação com as decisões de políticas macroeconômicas que acabamos de esboçar sucintamente.

Cabe sublinhar a importância da interface entre esfera político-econômica e mundos sociais do trabalho, interface onde se manifestam a criatividade gerencial e a autonomia relativa do campo da gestão. É nesta interface que o político se dota de meios de agir sobre o trabalho e sobre a saúde dos trabalhadores. É também o lugar pelo qual a gestão influencia as decisões de política econômica. Esta é a razão pela qual convém analisar as articulações entre as dimensões sociais do trabalho (notadamente a saúde) e a mudança com aspiração gerencial (técnica, organizacional ou regulamentar).

Examinemos neste sentido os aportes da sociologia do trabalho.

\section{II) Como compreender a mudança perpé- tua? Elaboração de uma grade de análise acerca da noção trabalho instituição}

\section{II- a) Aportes da sociologia do trabalho sobre o estudo da mudança}

Apoiando-se na leitura de diversos textos fundadores da sociologia do trabalho (FRIEDMANN, 1964; FRIEDMANN; NAVILLE, 1964; NAVILLE, 1963), mas igualmente sobre os comentários e as análises ulteriores, é possível destacar seus aportes mais importantes.

\section{A mudança como reflexo das relações sociais}

Os fundadores da sociologia do trabalho pretendiam recolocar o estudo do trabalho em uma perspectiva de conjunto: a que tipo de sociedade conduz o desenvolvimento da racionalização tecnicista? Para responder, apoiando-se em resultados de estudos empíricos conduzidos tanto na indústria, como nos setores agrário e terciário, os autores mobilizavam categorias de análise permitindo levar em conta a mudança social em uma perspectiva de luta para o acesso ao poder no seio de uma "sociedade global" e se interessavam pelos efeitos ambivalentes da industrialização nos países desenvolvidos e também no terceiro mundo. Se uma sociologia da organização e da empresa se distinguia, era no sentido de uma perspectiva e não de um campo ou de um domínio, sendo o essencial conservar ao trabalho toda sua complexidade.

Inscrevendo-se em uma tradição que remonta a Marx, os autores encararam o fato técnico no trabalho sob vários ângulos: como suporte de automação e de racionalização dos processos produtivos; como engendrando simultaneamente a desqualificação dos operadores e a requalificação de certos operários profissionais; e como agindo sobre as práticas de lazer dos operários (era um dos sentidos da alienação), assim como na prática sindical. A postura pretendida consistia, antes de tudo, não em se focalizar unicamente sobre o objeto técnico, nem somente sobre a situação de observação, mas em considerar o ambiente sócio-organizacional e socioeconômico eminentemente variável no qual se inscrevem as práticas profissionais.

Esta forma de abordagem lhes permitia ressaltar o caráter ambíguo dos efeitos da automatização: esta engendrava simultaneamente uma alienação acirrada e uma possibilidade de assegurar um controle mais maleável sobre o ciclo de produção. Do mesmo modo, o sentimento de estar menos preso a uma máquina convivia com a submissão maior à organização global da oficina ou da empresa. Preferindo falar de "fenômeno técnico", eles tinham igualmente apontado o quanto tal fenômeno concentrava a apropriação dos conhecimentos tácitos dos operários pela direção - via serviço de métodos.

Simultaneamente, os observadores estavam conscientes de que a atividade dos trabalhadores não estava totalmente determinada pela técnica e seus usos prescritos: eles reconheciam a existência de uma invenção e de uma engenhosidade entre os operadores. Entretanto, a identificação de práticas para contornar a situação por parte dos trabalhadores era levada às suas devidas proporções: uma iniciativa limitada em torno de um jogo inventado e controlado por outros. Neste sentido, eles destacavam que a restrição se exercia cada vez mais forte em função do aumento do número de transformações na organização: cada mudança constituindo-se, para os "executantes", como um lembrete da sua dependência.

Em suma, a sociologia do trabalho, particularmente até meados dos anos 1980, pela diversidade de seus 
esforços de análise, identificou a complexidade das interações entre mudança social na esfera do trabalho e mudanças tecnológicas que visavam à racionalização ampliada da produção. O acento colocado sobre as qualificações e o sistema de relações profissionais lembra que os usuários das tecnologias são primeiramente os trabalhadores, desigualmente repartidos em posições sociais rigidamente estruturadas e inscritos em trajetórias constrangidas.

Mas o que há de mais específico no estudo das TICs, no coração da racionalização gerencial contemporânea?

\section{O emprego e a renovação das TICs no coração da racionalização gerencial}

Desde meados dos anos 1950, Friedmann e Naville (1964) atribuíram à cibernética e ao computador papel central em suas reflexões. De fato, desde 1956, Friedmann considerava que a utilização das "calculadoras eletrônicas”, na automação, "parece a mais pesada das consequências para a condição do homem na civilização industrial" (FRIEDMANN, 1964, p. 15). Se Naville se mostrava otimista quanto à capacidade dos homens em conservar a livre disposição das técnicas que qualificava como experimentais, Friedmann notava que a cibernética, considerada como a ciência da eficácia da ação, pouco se interessava pelos homens aos quais ela dispensa, considerando máquinas e seres vivos como pertencentes à mesma classe, aquela dos organismos tendo atividades dirigidas a um objetivo.

Esta forma de abordar a articulação entre informática e trabalho se inscrevia em uma preocupação mais global no que diz respeito ao efeito social das "novas técnicas", revelando, no emprego crescente da informática, a emergência "de um novo tipo de civilização", caracterizado pela propensão à experimentação social e por "um remanejamento incessante das condições sociais". Eles tinham assim lançado as bases para a análise multidimensional da influência recíproca entre a evolução das tecnologias de informação e a mudança no trabalho.

No prolongamento destas perspectivas, certas pesquisas indicavam, desde o final dos anos 1970, que o emprego da informática estava a serviço da gestão, incorporando no processo tecnológico os princípios de rendimentos considerados como "historicamente válidos" (DURAND, 1978, p. 46), desde a análise do trabalho, decomposta em elementos simples, a unicidade da solução reputada ser a melhor, a especialização/parcelização, as transformações da organização a montante e a jusante que esta racionalização implica. Encontravam-se, assim, todas as dimensões da concepção taylorista do trabalho no ciclo (concepção, introdução, implementação) das máquinas informatizadas.

Nos anos 1990 e 2000, prosseguiu-se a abordagem, que evidencia as relações estreitas entre práticas gerenciais e o emprego das TICs. Neste sentido, estudando o teletrabalho, o ensino a distância, a informatização integrada das atividades de produção e de gestão ou groupware, as pesquisas se interessavam pelas intenções dos tecnologistas e pelas articulações entre técnica e sociedade. Elas mostravam como os diferentes tipos de dispositivos - técnicos e organizacionais - são de fato ferramentas de gestão, ou seja, de gestão dos homens e de coordenação hierárquica; portanto, reforço da capacidade de agir dos dirigentes. Uma das especificidades das TICs reside na sua contribuição à racionalização cognitiva, como ilustra o knowledge management. ${ }^{5}$ Além disso, elas:

permitem conciliar o que aparece atualmente como contraditório, até mesmo paradoxal: uma organização taylorista que dá autonomia aos operadores e procura sua implicação no trabalho, notadamente para mobilizar sua capacidade criativa. (CRAIPEAU, 2001, p. 22)

As modalidades de controle têm a particularidade de serem interiorizadas pela maioria dos trabalhadores que experimentam um sentimento de maior autonomia, pois cada um é encorajado a tornar-se um quase empreendedor no seio de coletivos efêmeros.

Partindo de constatações muito próximas, Durand (2004) insiste, de sua parte, sobre a importância das mutações do modelo produtivo fordista, resultando notadamente na mobilização das TICs para facilitar a difusão de métodos emprestados de certas indústrias japonesas. De fato, a empresa contratante é organizada em rede, externa em relação às empresas subcontratadas em cascata e interna entre os trabalhadores frequentemente distantes uns dos outros. Ela impõe o just in time, ou seja, a impossibilidade de fazer estoques, de gerenciar seu tempo de forma autônoma, tanto de seus fornecedores, quanto de seus operários, cujo trabalho é organizado em equipes com objetivos precisos. Mesmo que submetidos à pressão dos pares, os trabalhadores são simultaneamente gerenciados de forma individual e devem se considerar, alternadamente, como clientes e fornecedores uns dos outros.

O fluxo é intencionalmente dimensionado de maneira a aumentar sua própria fragilização. Este princípio de fragilidade permite inscrever o projeto disciplinar diretamente nos tempos dos ciclos e a sensibilidade nos riscos de ruptura. Os trabalhadores, sentindo-se responsáveis, pessoalmente, por qualquer interrupção do fluxo de trabalho, mobilizam-se permanentemente para atingir os objetivos produtivos, mas também para aperfeiçoar implacavelmente os procedimentos, a qualidade e as ferramentas, o que provoca estresse e sentimento de insegurança permanente, pois o fluxo não deve parar, conforme a disciplina implícita. É neste quadro que a introdução gerencial das TICs ganha todo seu sentido: as direções esperam, graças às TICs, aumentar a produtividade e aumentar a reatividade, assim como a rastreabilidade. Seu papel é de fluidizar as trocas de informação e contribuir para a padronização da comunicação. 
Em certas situações limites, como a das centrais de atendimento telefônico, o objetivo é reduzir o trabalho de interpretação inerente a toda comunicação verdadeira e acionar automaticamente, nos trabalhadores, a execução de um procedimento padrão desde a aparição de um sinal. Outros trabalhos sobre as centrais de atendimento ou sobre as organizações just in time colocam em evidência a irredutível capacidade dos trabalhadores em contornar o sistema de controle introduzido com as TICs. Mas é necessário sublinhar o quanto estas zonas de autonomia são limitadas, frágeis, sensíveis às transformações sucessivas da organização do trabalho, pois a gerência das centrais de atendimento sabe também contornar as estratégias de contorno dos operadores de teleatendimento (VENCO, 2009).

Estas reflexões mostram o quanto a compreensão da articulação entre TICs e o trabalho ganha em considerar as relações de dominação subjacentes à aparente autonomização dos trabalhadores. Mais precisamente, somente um subconjunto de manipuladores de símbo$\operatorname{los}^{6}$ pode se revelar vencedor entre os que participam da concepção e da implementação das reestruturações contínuas presentes por que passam as empresas. Esta posição lhes dá, de fato, a capacidade de rever o poder de negociação dos outros trabalhadores (GOLLAC; KRAMARZ, 2000; VALENDUC, 2009).

\section{Quatro eixos para analisar a vontade de mudar perpetuamente as organizaçóes}

Estes esclarecimentos mostram que as perspectivas abertas pela sociologia do trabalho fornecem um rico quadro de análise da interação entre evoluções dos mundos sociais do trabalho e mudanças técnico-gerenciais acerca das TICs. Quatro dimensões particularmente estruturantes destacam-se:

- O eixo da racionalização da coordenação. Neste eixo, é possível indicar a alavanca organizacional que as TICs oferecem aos dirigentes e aos gestores na sua vontade de reconfigurar os coletivos. Este eixo permite igualmente identificar a capacidade de certos grupos profissionais de se apoiar nos mesmos dispositivos para inventar novas práticas;

- O eixo da racionalização dos conhecimentos. Aqui, a utilização das TICs é analisada como um meio de relançar o projeto de racionalizar a gestão dos conhecimentos (knowledge management, comunidades de práticas), considerando-se o que implica na reprodução das desigualdades face ao controle dos dispositivos técnicos;

- O eixo da racionalização axiológica. Permite questionar o grau e o sentido da autonomia no trabalho com as TICs. As sucessivas ondas de injunção à autonomia, de autonomia controlada, formas recentes de racionalização, acompanhadas de uma aparelhagem de supervisão em tempo real, não de- sestabilizam as margens da autonomia autêntica identificada por certos observadores?;

- O eixo da racionalização das relações de dominação. Este eixo permite apreciar em que medida a inscrição das relações sociais de produção na renovação das regras de gestão, dos equipamentos e da arquitetura da informática constitui uma nova forma de legitimação da dominação, prolongando o trabalho de incorporação das relações hierárquicas na técnica, já identificada no caso da automação.

Estes quatro eixos não são, no entanto, independentes uns dos outros. Pode-se considerar que a racionalização das relações de dominação se apoia nos três outros eixos e que ela contribui, em contrapartida, a reforçá-los. Assim, pode-se pensar que o controle da concepção, da introdução, do emprego e da renovação dos dispositivos técnico-gerenciais se enriquece pelo pertencimento aos coletivos perenes e pertinentes, pelo domínio das competências técnicas e organizacionais, assim como pela disposição em preservar as margens de autonomia. Em contrapartida, este controle reforça os coletivos que o iniciam, os mantêm em uma dinâmica de aprendizagem e de ação criadora.

Pode-se então considerar estas quatro dimensões como os componentes de um quadro de análise que permite considerar, de forma geral, as articulações entre a mudança técnico-gerencial e as evoluções da saúde no trabalho. Todavia, para colocar em evidência as dinâmicas, os processos e as transformações sem pré-julgar seus sentidos, é necessário para nós dotar de "referências" cada um dos eixos por meio do quê poderemos medir, apreciar os intervalos entre dois períodos de observação. Mas antes de expor rapidamente quais poderiam ser estas referências, resta-nos dar um fundamento rigoroso, lógico à existência destes quatro eixos.

\section{II- b) Aportes do conceito instituição trabalho}

Nesta perspectiva, é interessante notar que estes eixos da racionalização podem ser considerados como a transposição, no mundo do trabalho, de quatro funções maiores que:

Durkheim atribui [...] às instituições: a integração (a articulação entre indivíduo e sociedade), a regulação (produção de regras que regem a vida social), a emancipação (afirmação da personalidade individual) e, enfim, a codificação (construção de nossas categorias de entendimento). (LALLEMENT, 2003, p. 13 e 53-57)

Em outros termos, uma chave de explicação, que permite vincular sociologicamente as quatro dimensões, consiste em admitir que o trabalho é uma instituição social. Assim, compreender - e eventualmente melhorar - a saúde psíquica dos trabalhadores equivale a examinar os efeitos complexos da racionalização gerencial sobre cada uma de suas funções/dimensões.

${ }^{6}$ N.T.: Os “manipuladores de símbolos”, expressão proposta por Reich (1993), designa trabalhadores intelectuais, executivos, professores, pesquisadores, consultores, advogados, artistas que manipulam informações, conhecimentos. 
Precisemos que, se de um lado, a categoria instituição permite apreender o que há de estável e de estruturante no social, ela não designa, no entanto, as realidades imutáveis, eternas e que se impõem a todos da mesma maneira. Ao contrário, a maneira como as instituições concretas se transformam constitui um revelador das evoluções sociais mais gerais. Por isso, é muito pertinente interessar-se pelos processos de institucionalização e desinstitucionalização.

É nesta dupla perspectiva que Lallement (2003) revisita a concepção durkheiminiana deste conceito, conforme citado anteriormente, considerando as quatro funções maiores das instituições. Mais exatamente, procuraremos estabelecer em que medida a mudança permanente se opõe aos efeitos da institucionalização ligados ao trabalho e em quê a renovação técnico-gerencial pode se revelar uma fonte de desinstitucionalização.

Considerada desta forma, a categoria instituição trabalho fornece os fundamentos para articular logicamente não somente as quatro dimensões que fazem o objeto da racionalização, mas igualmente os quatro eixos de análise que procuramos definir. Dito isto, para tornar mais operacionais os quatro eixos de análise, vamos lhes fazer corresponder as dinâmicas sobre as quais iremos identificar e qualificar os momentos-chave que serviram de "graduação" para apreciar a forma e a amplitude das transformações do trabalho, elas mesmas na origem das evoluções da saúde psíquica dos trabalhadores.

\section{II- c) Elaboração de uma grade de análise da mudança perpétua}

Este esforço de clarificação, do qual apresentaremos aqui apenas resultados sintéticos, parece-nos necessário, pois é frequente termos próximos (rede, comunidade, coletivo, por exemplo) ou automaticamente opostos (autonomia e controle, por exemplo) serem utilizados sem que os autores se dediquem a defini-los enquanto categorias de análise, de sorte que controvérsias ou convergências mostrem-se fundadas sobre mal-entendidos.

Neste sentido, ao estudo da racionalização da coordenação, propomo-nos fazer corresponder o problema de compreender a dinâmica das capacidades de elaborar e de se inscrever nos coletivos. Como dispomos de pouco espaço, não poderemos entrar aqui no detalhe da demonstração. Retemos que, em uma situação empírica dada, para apreciar em que medida a renovação dos dispositivos técnicos tem influenciado a capacidade dos trabalhadores para se inscreverem em coletivos de trabalho perenes e pertinentes, pode-se identificar quatro coletivos-tipo cujas características podem ser comparadas aos dados resultantes da observação, os quais são definidos de maneira a compreender um espectro que abarca:

- da anomia (grau zero de elo social, etapa última da desintegração);
- até a comunidade de profissionais (hierarquia, regras de inclusão e de exclusão, exigência de implicação);

- passando pela rede estratégica (os membros são movidos por um único interesse); $\mathrm{e}$

- a rede de suporte (onde a dimensão afetiva e a atenção aos outros assumem um relevo crescente). ${ }^{7}$

Seguindo o mesmo esquema de raciocínio, ao estudo da padronização dos conhecimentos corresponde o problema de compreender a dinâmica das capacidades para se inscrever no processo de aprendizagem. Aqui ainda, sem desenvolver o argumento, indicamos que se trata de se dotar de um dispositivo de análise que permite apreciar a evolução das capacidades de aprendizagem dos trabalhadores no contexto de renovação tecnológica. Neste sentido, é possível identificar quatro formas de aprendizagem-tipo cujas características podem ser comparadas aos dados colhidos durante estudos de campo. Estas "referências" balizam um leque que abrange:

- da aprendizagem individual (reorganização dos esquemas que levam a generalizações crescentes, dependente dos aspectos afetivos, mas também da identificação, pelo sujeito em aprendizagem, de um sentido para o seu esforço cognitivo e do reconhecimento institucional do esforço de adaptação cognitiva);

- à aprendizagem coletiva (aquisição de competências coletivas, regulação dos coletivos);

- passando pelo desaprender individual (perda de saberes e saber-fazer e/ou entrave à aquisição de novos saberes e saber-fazer); e

- pelo desaprender coletivo (perda de competências coletivas e/ou entrave à aquisição de regulação dos coletivos). ${ }^{8}$

No que diz respeito ao estudo da racionalização axiológica, podemos lhe fazer corresponder a preocupação de compreender a dinâmica das capacidades do agir autônomo. Este eixo de análise permite apreciar os efeitos acumulados da renovação técnico-organizacional sobre as capacidades individuais e coletivas de auto-organização dos trabalhadores para controlar a mudança e dominar o emprego dos dispositivos baseados nas TICs. Distinguiremos quatro momentos-chave cujas características detalhadas permitem posicionar as situações empíricas em um continuum:

- da independência (a forte capacidade de autoinstituição está articulada a um projeto profissional portador e permite conceder/retirar o reconhecimento);

- à dependência (o indivíduo depende do suporte de outros sem poder retribuir; ele não pode 
negociar sua cooperação e suas capacidades de iniciativa são pouco valorizadas);

- passando pela autonomia (os indivíduos são mais ligados à empresa e aos seus pares, mesmo que sua capacidade de autoinstituição permaneça significativa, notadamente graças a sua inscrição em um coletivo perene e sua capacidade de aprendizagem); e

- a resignação (fraca capacidade de autoinstituição, resultado de experiências truncadas impedindo a acumulação de recursos e a adaptação aos dispositivos adquiridos). ${ }^{9}$

Quanto ao estudo da racionalização das relações de dominação, este corresponde à dinâmica das capacidades para controlar a mudança técnico-organizacional permanente. Sobre este eixo, é possível identificar quatro posições-chaves delimitando um conjunto de trajetórias, que aborda:

- da instauração (capacidade de agir sobre a ação dos atores de forma mais duradoura e mais extensa, graças à produção recorrente de injunções para mudar e à prática de experimentação);

- à exclusão (acumulação, durável, das posições mais desfavoráveis em cada uma das dinâmicas);

- passando pelo pessoal auxiliar (os auxiliares identificam as modalidades finas, permitindo implementar a renovação técnico-organizacional; eles não hesitarão em instrumentalizar seus colegas); e

- à subordinação (execução das ordens, o que não exclui - e às vezes mesmo exige - uma parte de iniciativas limitadas).

Estas quatro dinâmicas, tornadas operacionais pela identificação dos indicadores sociais (as referências), possuem elementos comuns: as aprendizagens são parcialmente ligadas à inscrição em um coletivo, as capacidades de agir ligadas às aprendizagens e à inscrição em um coletivo; quanto às relações de dominação, resultam dos outros três e com eles interagem.

\section{III) Utilização da grade de análise para investigar os efeitos da mudança perma- nente sobre a saúde dos trabalhadores}

O conceito de instituição-trabalho, assim definido, permite, então, ao pesquisador apreender como, na medida em que avançam as transformações técnico-gerenciais, parte dos trabalhadores pode progressivamente entrar em um círculo gerador de degradação de seu estado psíquico.
Com efeito, no caso da França, utilizamos esta grade de análise para considerar as transformações no campo da educação (em torno das inovações técnico-gerenciais como os campi digital, a distribuição de laptops nos colégios, dentre outras), no setor hospitalar (em torno da introdução do prontuário informatizado, da gestão dos Centros de Diagnóstico e Imagens e das abordagens de qualidade) e no seio de uma grande empresa de telecomunicações (estudando particularmente a implantação de reformas sucessivas sobre o estatuto, as reestruturações, os modos de gestão de pessoal e, também, a prática do teletrabalho entre os quadros e a evolução das relações de ajuda nas centrais de atendimento) (METZGER, 2000, 2007b; METZGER; CLEACH, 2004).

Mais precisamente, mobilizamos esta grade de análise em quatro grupos de pesquisas sobre os universos profissionais:

- uma multinacional do setor de telecomunicações cujos trabalhadores têm vivenciado há mais de 20 anos uma série de ininterruptas reformas e de reestruturações, mudanças de estatuto, reconversão de profissionais técnicos para o setor comercial etc. Procedendo por entrevistas semiestruturadas junto aos quadros técnicos e administrativos, técnicos, vendedores e pessoal administrativo, cerca de 80 trabalhadores foram contatados entre 1997 e 1999 e, mais tarde, entre 2004 e 2006;

- diversas pesquisas no setor da educação/formação: escolas primárias, secundárias, universidades e formação interna nas empresas. Interessamo-nos particularmente pelas transformações das práticas profissionais quando da introdução de novos dispositivos técnicos (ensino a distância, formação em informática, programas de gestão de suporte das aulas, dentre outros). Procedendo igualmente por entrevistas semiestruturadas junto aos profissionais (professores, formadores, coordenadores pedagógicos e técnicos em informática), aproximadamente 50 foram entrevistados entre 2002 e 2004 e, posteriormente, em 2006;

- várias pesquisas no setor hospitalar, sempre nos interessando sobre os efeitos dos dispositivos técnico-gerenciais sobre as práticas dos profissionais (médicos, enfermeiras, quadros da saúde). Notadamente, durante estudo sobre a informatização de um hospital parisiense, realizamos cerca de 40 entrevistas entre 2005 e 2006;

- várias pesquisas sobre a inserção de trabalhadores com deficiência visual e auditiva em uma grande empresa. Interessamo-nos pelos efeitos da renovação dos equipamentos de informática na sua inserção, entrevistando, além deles, colegas, seus superiores, formadores e técnicos de informática, totalizando 40 pessoas, entre 2003 e 2004.

${ }^{9} \mathrm{~A}$ construção desta grade de análise figura em Lallement e Metzger (2009). 
As entrevistas foram, frequentemente, complementadas com observações nos serviços respectivos.

Sem poder aqui restituir a riqueza dos resultados, guardemos que, em cada uma das configurações (educação, saúde, telecomunicações), devido a suas trajetórias profissionais e sociais anteriores, sob o efeito de uma sucessão de renovações no contexto de trabalho (dispositivos técnicos, regras de gestão, reorganizações etc.), numerosos indivíduos estavam profundamente desestabilizados. Pudemos, assim, notar, no seio de cada grupo profissional (professores, engenheiros biomédicos, médicos, quadros técnicos e comerciais, teleoperadores), fenômenos de competição/ concorrência entre colegas, levando à desclassificação relativa, à incapacidade de se projetar no futuro. Estes trabalhadores eram incapazes de se inserirem nos novos coletivos perenes e pertinentes (vis-à-vis o novo ambiente), de entrar em um processo de aprendizagem coletiva e de desenvolver um projeto de autoinstituição. Eles acumulavam atrasos e um sentimento de isolamento crescente (desvinculação) que não lhes permitia nem se associar para influenciar a produção de regras estruturantes (exclusão), nem negociar sua cooperação (sujeição).

É importante notar que a perda das solidariedades entre os trabalhadores está intimamente ligada ao processo de racionalização técnico-gerencial. Com efeito, à medida que as reestruturações, as reconversões, as mudanças de vínculos e, também, as aposentadorias antecipadas dos trabalhadores mais velhos se sucediam, as organizações sindicais enfraqueciam-se de modo considerável. Assim, o hábito de se organizar coletivamente para pressionar as direções a negociar foi aos poucos perdido. ${ }^{10}$ Soma-se a isto o fato de que, graças à renovação dos dispositivos de gestão de pessoal, as direções tomaram pouco a pouco o controle sobre os processos de transmissão de saberes e do saber-fazer. Fossem formadores, engenheiros hospitalares, quadros técnicos ou teleoperadores, parte destes profissionais foi confrontada - cedo ou tarde - com uma perda de sentido de sua atividade (ministrar curso concebido por outros, passar todo o tempo redigindo relatórios de atividade, não se permitir repousar, respeitar roteiros rígidos e inapropriados). Todos estes fatores são, então, reunidos para se opor a seus esforços em se manter com saúde e vão, pouco a pouco, manifestar os sintomas característicos das DPS, chegando mesmo ao suicídio. ${ }^{11}$

Ao contrário, quando estão inscritos em uma rede de suporte, seja uma comunidade de profissionais - estes coletivos, podendo mesmo se estender a outras organizações, outros hospitais, outras empresas do mesmo setor -, parte dos trabalhadores pode tirar pro- veito das oportunidades que representam, para eles, a mudança técnico-organizacional e chegar a resistir psiquicamente aos riscos.

As articulações entre saúde e trabalho e transformações técnico-gerenciais são, portanto, ambíguas. No hospital, nos estabelecimentos de ensino, entre os teleoperadores ou os quadros que adotaram o teletrabalho, em toda a parte é possível revelar a existência dos processos de desinstitucionalização do trabalho. Simetricamente, é possível identificar processos que favoreçam a inserção em coletivos perenes, em uma dinâmica de aprendizagem coletiva e de independência. Pode-se falar, então, de polarização das posições para caracterizar o fato de que, sobre um longo período, assistimos a um fortalecimento das capacidades de certos grupos profissionais e de certos indivíduos em se manter em bom estado de saúde, enquanto que, simultaneamente, outra parte perde, pouco a pouco, o acesso aos recursos coletivos para resistir ao desgaste e ao aumento das DPS.

Assim, o modelo de análise proposto permite explicar o vínculo estreito entre saúde e trabalho e a vontade técnico-gerencial de mudar em permanência todas as dimensões da atividade. A degradação da saúde psíquica de parte dos trabalhadores é devida à intenção obstinada da gestão de controlar os trabalhadores colocando-os em um tipo de movimento perpétuo. Desde então, para reduzir os efeitos nocivos sobre a saúde desta desestabilização organizada do trabalho, é necessário compreender o fenômeno gerencial participante da mudança permanente.

\section{IV) As duas fontes da mudança permanente}

\section{IV-a) A uma dinâmica própria do fenômeno gerencial}

Nesta perspectiva, lembremos que a gestão se apresenta $^{12}$ como uma maneira mais racional de decidir e de organizar. Ela aspira constituir uma saída, racionalmente fundada, ao arbitrário, ao nepotismo, à negligência, ao desperdício. No presente, ela constitui um modo de organização e de comando cujos princípios são frequentemente bem recebidos, mesmo por aqueles que identificam os efeitos disfuncionais de sua aplicação.

Sua especificidade é agir do exterior, em posição mais elevada. Fazendo-o, intencionalmente ou não, ela expropria os atores da definição da finalidade mesma de sua atividade: o fenômeno gerencial "racionaliza" não somente certas dimensões de sua atividade, mas orienta - por essência - sua ação em uma direção na qual eles não escolheram.

Convém falar do fenômeno gerencial, pois a gestão excede o simples quadro de um conjunto de ferramentas e de técnicas apresentadas como cientificamente

\footnotetext{
${ }^{10}$ Nós encontramos aqui um resultado identificado por Linhart (1996).

${ }^{11}$ Trabalhando sobre as mesmas empresas, Burgi (2009) chega a constatações próximas.

${ }^{12}$ E apresenta efetivamente a vantagem em certas situações.
} 
elaboradas. Ela inclui igualmente discursos e representações. Sobretudo, ela se encarna nos atores coletivos que concebem os seus princípios, presidem ao ajuste das ferramentas, desenvolvem técnicas de justificativas de seu emprego etc.

Visto por este ângulo, os "gestores" podem ser considerados como um conjunto de grupos profissionais, parcialmente em competição, visando ao monopólio do conhecimento da boa maneira de organizar o trabalho de outros profissionais. Em decorrência, eles se colocam em posição conflituosa em relação a estes últimos. O fenômeno gerencial pode, então, ser vislumbrado de modo dinâmico como tensão, luta permanente entre dois sistemas de dispositivos (técnicos, organizacionais, simbólicos, dentre outros):

- o primeiro sistema é concebido, às vezes, de maneira informal, outras, de modo altamente codificado por profissionais cuja atividade principal não é a gestão, mas que, para conduzir bem seu próprio trabalho produtivo, encontraram meios de se organizar, de hierarquizar as diferentes dimensões de seu ofício. As soluções elaboradas por estes profissionais se inserem na concepção do trabalho bem feito, de acordo com os valores dominantes de seu grupo, e se inscrevem em longo prazo, por exemplo, considerando a necessidade de formar os novos e de promover os mais antigos;

- o segundo é concebido e aplicado por diversos grupos profissionais (administradores titulados, engenheiros, de informática, dentre outros) que procuram fundar sua legitimidade sobre sua capacidade de definir o mais racionalmente possível a eficácia coletiva em meio organizado e simultaneamente buscam assim exercer o poder nos aparelhos produtivos, em especial controlando suas transformações. Mesmo se o emprego dos dispositivos de gestão resulta de acordo entre as diversas partes envolvidas, sua concepção e introdução dependem da atividade dos gestores.

Dessa forma, a extensão do fenômeno gerencial resulta antes de tudo de uma história, aquela dos grupos profissionais intervindo no campo da gestão das organizações (campo heterogêneo, composto de segmentos hierarquizados e parcialmente em concorrência), de seus predecessores, de seus aliados (dirigentes, outros profissionais ganhando no curto prazo com o desenvolvimento da gestão), das instituições onde eles se formam (grandes écoles, ${ }^{13}$ escolas de gestão, disciplinas de gestão ministradas no seio de outras carreiras especializadas), de firmas de consultoria e de empresas que desenvolvem dispositivos de gestão. Este processo se apresenta como o resultado, sempre contingente, mas jamais indeterminado, de relações sociais entre os dois sistemas com suas recomposições internas, acompanhadas de deslocamentos de grupos profissionais de um sistema a outro.

Junto a esta estruturação complexa, a dinâmica própria no campo da gestão e as tensões entre grupos se manifestam, notadamente, por uma dinâmica de renovação incessante de dispositivos, o que tem por consequência levar os dirigentes e a elite gerencial a se centrarem em uma forma particular de objetividade, aquela que visa à leitura e às discussões em torno de indicadores, dos sistemas de controle/comando, ${ }^{14}$ de resultados contábeis etc. Esta focalização sobre as representações redutoras, frequentemente conectadas de modo frágil com a realidade do trabalho, explica em parte a lenta degradação da saúde psíquica dos trabalhadores.

Outra fonte estrutural dos distúrbios psicossociais deve ser pesquisada no seio do pensamento racionalizador.

\section{IV-b) Uma dinâmica própria ao pensamento raciona- lizador}

Com efeito, se a mudança permanente é finalmente colocada em obra, é também porque uma parte significativa dos trabalhadores não se opõe a seu desenvolvimento e à sua renovação. Certamente, as desestabilizações sucessivas ligadas às inovações técnico-gerenciais reduzem as capacidades de coalizão, engendram resignação e indiferença. Quanto aos trabalhadores que se engajam em uma crítica argumentada sobre a introdução dos dispositivos, eles o fazem em nome da defesa do que existe, de um ethos profissional. É para eles, todavia, sempre difícil criticar a fundo a gestão; e a referência a valores não parece frequentemente contrabalancear a força de convicção sobre a qual se apoia a gestão.

Se esta última recebe um eco com frequência favorável, é ela que está inscrita nos princípios e nos discursos que se referem a justificativas científicas. Discursos, princípios, ferramentas apresentam todas as aparências da familiaridade e da lógica a mais rigorosa, graças notadamente:

- à quantificação (concepção aparentemente neutra de indicadores, cálculos aparentemente transparentes do seu valor, elaboração de painéis de controle, fixação de objetivos reforçando a necessidade de quantificação, avaliação do alcance dos objetivos por meio de uma discussão acerca do desvio entre dois números);

\footnotetext{
${ }^{13}$ N.T.: As Grandes Écoles integram o sistema público de ensino superior, contudo separadas das universidades francesas. A despeito de representarem uma parcela ínfima neste segmento, abarcam 30\% do total do orçamento das universidades e 5\% do total de estudantes universitários. Seus alunos são formados para ocupar cargos importantes da administração pública ou para a alta gestão das maiores empresas. Entre as mais conhecidas, podem ser citadas a École National d'Administration (ENA), as Écoles Normales Superieures, a École Polytechnique, dentre outras.

${ }^{14}$ N.T.: tableau de bord, no texto original em francês.
} 
- às representações gráficas (baseadas em valores dos indicadores e, cada vez mais, sobre as relações entre indivíduos por meio de gráficos de redes);

- também aos conhecimentos das ciências sociais, regularmente instrumentalizadas desde a preconização da escola de relações humanas até os conselhos para elaborar as comunidades de práticas ou empregar ferramentas de gestão do conhecimento.

Ora, sob esta aparência de racionalidade científica, se perfila, bem frequentemente, uma postura de reificação. Para mostrá-la, resgatemos em primeiro lugar os elementos subjacentes à prática gerencial da mudança permanente.

\section{Os traços característicos que subtendem a vontade de mudar}

Mesmo que as direções encomendem pesquisas para coletar opiniões ou saber o que foi "sentido" pelos trabalhadores, mesmo que elas solicitem, às vezes, as sugestões dos trabalhadores, elas não elaboram, contudo, a mudança de modo conjunto. E longe de fazer evoluir sua forma de pensar a organização, os dirigentes e as gerências utilizam, frequentemente, os resultados destas enquetes para "ensinar" novos valores e práticas: desde o culto do serviço ao cliente, até a aceitação da competição como ideal de relação, passando pela adesão ao movimento ou à ajuda a gerenciar o estresse.

Tudo se passa então como se o alto escalão, por pretender modelar à vontade o trabalho, concebesse os mundos sociais da empresa como "coisas", constituídas de "partículas" elementares que são:

- tanto os indivíduos (individualização dos modos da gestão de recursos humanos e os objetivos, contagem dos efetivos, flexibilização externa);

- como as atividades (organização científica do trabalho, divisão do funcionamento da empresa em processo e "competências", flexibilização interna);

- quanto as entidades organizacionais de base (fusões, absorções, reestruturações, subcontratação, projetos).

As práticas profissionais que ligam entre elas estas partículas são julgadas redutíveis a um conjunto finito de práticas elementares (as instruções, as metas, os contratos, os empregos-tipos), que podem fazer parte de um diagrama de fluxo, uma lista de processos, uma tabela de dados, visando a sua simplificação e a sua tradução em indicadores antes da automatização em uma fase ulterior.

As TICs reforçam as modelagens com a possibilidade de rastreamento, contagem instantânea, alimentação de bases de dados consultáveis pelos organizadores. Além do quê as comunicações, as trocas, sejam vocais ou escritas, podem ser registradas e analisadas segundo esquemas padronizados que supõem refletir o grau de cooperação.

Acrescentamos que os dirigentes e a elite gerencial consideram a história e a cultura, as construções sociais produzidas pela experiência, como um freio à eficácia coletiva. Cada etapa da vontade de mudança parece anular a herança do passado, sendo apresentada como um meio de resolver as disfunções que dele decorrem.

Estas características que estão por trás da ação dirigente apresentam numerosas analogias com uma atitude reificante.

\section{A reificação ou a transmutação do social em coisa}

Com efeito, a reificação implica que se recuse (ou que se torne incapaz) a se colocar no lugar do outro na interação. No limite, a reificação conduz ao desaparecimento das interações, porque não há mais intersubjetividade (HONNETH, 2007). A atitude reificante consiste em renunciar a toda preocupação em direção ao outro, em recusar o reconhecimento de sua dimensão humana. Ela permite aos portadores desta atitude não se sentirem concernidos pelas consequências de seus atos, sobretudo quando estes últimos se manifestam de forma qualitativa.

E uma vez que o social é considerado como uma coisa, as mesmas regras são consideradas - pelos autores da reificação - como aplicáveis aos dispositivos técnicos, às trocas comerciais, às interações sociais e às normas sociais da ação. Os que dominam estes tipos de regras e controlam seu emprego podem, portanto, agir intencionalmente sobre o social para conformá-lo a um modelo preestabelecido.

Dito de outra forma, a postura reificadora joga-se sobre dois planos entrelaçados. De um lado, ela intervém recorrendo aos princípios científicos de desinteresse, de não-engajamento, princípios a serviço do "conhecimento objetivante" ou conhecimento instrumental do social: aqui, o elo social, a aprendizagem , os saberes e o saber-fazer profissionais, as aspirações à autonomia, todos estes elementos são considerados como componentes destacáveis de seu substrato intersubjetivo.

Por outro, a reificação se exerce no momento da concepção e da implementação dos dispositivos de gestão, tornando-se habitual para agir sobre o social, como se pudesse conformá-lo a um plano, discipliná-lo segundo esquemas preexistentes, chegando a incluir, entre os esquemas, mecanismos de retroação para corrigir os desvios em relação à trajetória desejada (avaliação contínua, rastreabilidade).

\section{A reificação fonte da experimentação gestionária}

Assim definida, a reificação permite considerar as características que dão suporte à prática gerencial da mudança permanente. Isto porque o social pode ser legitimamente considerado como uma coisa, constituída de uma hierarquia de partículas nos mecanismos transparentes e sem histórias que se pode procurar 
conformá-lo a um plano preestabelecido. O fenômeno gerencial se inscreve perfeitamente no processo:

de autonomização das práticas que consistem simplesmente em observar os homens, a registrar friamente sua existência, a considerá-los como fatores independentes do contexto do mundo vivido ao qual eles pertencem. (HONNETH, 2007, p. 116) ${ }^{15}$

A prática da mudança perpétua força os trabalhadores a mobilizarem sua própria subjetividade, deixando-se convencer ou fingindo estarem convencidos do bem fundado da atitude reificadora (p. 114). Pensamos aqui nos dispositivos de recrutamento e de avaliação permanente cuja implementação pressupõe o consentimento formal dos próprios trabalhadores, que fingem experimentar certos sentimentos esperados ou, ao contrário, que não experimentam nenhum estado de espírito (por exemplo, quando colaboram com a avaliação de seus pares ou subordinados, quando eles fazem reestruturações, demissões).

Daí em diante, os processos de desinstitucionalização parcial do trabalho fincam suas raízes nesta postura de reificação, comum às abordagens científicas e à ação gerencial. Como é legítimo considerar o social como uma coisa, torna-se legítimo considerar o elo social como uma coisa, pode-se considerar como sendo razoável mudar sem cessar o trabalho, o qual desempenha cada vez menos suas funções de integração, de codificação, de regulação e de emancipação.

\section{Conclusão}

Neste contexto, para que formas de ação possam contribuir para reduzir as consequências deletérias da organização sobre a saúde, seria necessário poder abrandar a mudança perpétua e orientá-la em direção a uma concepção mais respeitosa das intersubjetividades, do social. Ora, vimos que a mudança perpétua resulta da dinâmica interna no campo da gestão (competição entre gestores, conflito com outros grupos), que ela se desdobra a partir de um conhecimento objetivante do social (atitude reificante, negação de intersubjetividade) e que ela se aperfeiçoa sem cessar pela prática da experimentação social. Daí em diante, para aperfeiçoar de forma autêntica a saúde psíquica dos trabalhadores, seria necessário que os tomadores de decisão se "reconectassem" à realidade, que eles reconhecessem a intersubjetividade, a riqueza de seus aportes e que permitissem a todos os trabalhadores conquistar as capacidades duradouras a serem experimentadas.

Isto seria, finalmente, renunciar ao controle da mudança, que é precisamente o desafio das relações de dominação no trabalho. Encontramos, ao final das contas, uma evidência: buscar tornar o trabalho emancipador para a maioria é poder intervir no coração das relações sociais do trabalho, tal como se expressam na articulação entre economia e gestão, entre as decisões da política macroeconômica e a definição precisa dos contextos da ação.

\section{Agradecimentos}

O autor agradece à Selma Venco pela qualidade de seu trabalho de tradução e por sua paciência com revisões sucessivas deste artigo.

\section{Referências}

ASKENAZY, P. et al. Organisation et intensité $d u$ travail. Octarès: Toulouse, 2006.

BOSCH, G.; SCHIEF, S. L'emploi des 55 ans et plus en Europe entre work line et préretraiite. Travail et Employ, n. 107, p. 19-32, juil.-sept. 2006.

BURGI, N. La maltraitance au travail est-elle programmée ? Les paradoxes d'une gestion "responsable" des ressources humaines à France Télécom. In: JOURNÉES INTERNATIONALES DE SOCIOLOGIE DU TRAVAIL, 12., Juin 2009, Nancy. Résumés et textes des communications... Nancy: Gree, 2009. Disponível em: <http://gree.univ-nancy2.fr/encours/digitalAssets/51648_ BURGIJJST2009.pdf> . Acesso em: 11 mar. 2011.
CRAIPEAU, S. L'entreprise commutante ou travailler ensemble séparémen. Paris: Lavoisier, 2001.

DAUBAS-LETOURNEUX, V.; THÉBAUD-MONY, A. Organisation du travail et santé dans l'Union Européenne. Luxembourg: Fondation Européenne pour l'Amélioration des Conditions de Vie et de Travail, 2002.

DANIELLOU, F.; ESCRIVA, E. Les conditions d'une prévention pérenne. Agence Nationale pour l'amélioration des conditions de travail. 2008. Disponível em: <http://www.anact.fr/portal/pls/portal/ docs/1/748333.PDF > . Acesso em: 13 abr. 2011.

DEBOUT, F. et al. La santé à l'épreuve du travail. Mouvements, v. 2, n. 58, p. 7-12, 2009.

\footnotetext{
${ }^{15}$ Foucault (1975) havia igualmente identificado a existência destes mecanismos de objetivação (registros, compatibilidade, transmissão de dados) analisando as técnicas de disciplinarização dos corpos, com progressividade e seu caráter acumulativo (grade de espaço de tempo, controle permanente ou crença na permanência do controle).
} 
DEBRAND, T.; LENGAGNE, P. Pénibilité au travail et santé des seniors en Europe. Économie et Statistique, n. 403-404, p. 19-38, 2007.

DURAND, C. Le travail enchaîné, organisation du travail et domination sociale. Paris: Seuil, 1978.

DURAND, J.-P. La chaîne invisible. Travailler aujourd'hui: flux tendu et servitude volontaire. Paris: Seuil, 2004.

FOUCAULT, M. Surveiller et punir. Naissance de la prison. Paris: Gallimard, 1975.

FRIEDMANN, G. Le travail en miettes. Paris: Gallimard, 1964.

FRIEDMANN, G.; NAVILLE, P. Traité de sociologie $d u$ travail. Paris: Armand Colin, 1964.

GAULEJAC, V. La société malade de sa gestion Idéologie gestionnaire, pouvoir managérial et harcèlement moral. Paris: Seuil, 2005.

GOLLAC, M.; KRAMARZ, F. Linformatique comme pratique et comme croyance. Actes de la Recherche en Sciences Sociales, n. 134, p. 4-21, 2000.

GOLLAC, M.; GUYOT, S.; VOLKOFF, S. À propos du "travail soutenable". Les apports du séminaire interdisciplinaire emploi soutenable, carrières individuelles et protection sociale. Rapport du CEE, n. 48. Noisy-le-Grand. Centre d'études de l'imploi. Juin 2008. 147 p. Disponível em: <http://www. cee.recherche.fr/fr/rapports/48-travail-soutenableseminaire-interdisciplinare-carriere-individuelleprotection-sociale.pdf $>$. Acesso em: 11 mar. 2011.

HONNETH, A. La réification. Paris: Gallimard, 2007.

LALLEMENT, M. Temps, travail et modes de vie. Paris: PUF, 2003.

LALLEMENT, P.; METZGER, J.-L. Renouvellement technologique et inégalités numériques au travail. In: LELONG, B.; GRANJON, F; METZGER; J.-L. Inégalités numériques, clivages sociaux et modes d'appropriation des TIC. Paris: Hermès-Lavoisier, 2009. p. 159-192.

LINHART, D. Souffrance individuelle et action collective. In: DURAND, J.-P. Le syndicalisme au futur. Paris: Syros, 1996. p. 57-78. (Collection Alternatives Sociologiques)

LUNDBERG, I. et al. Work and social inequalities in health in Europe. Bruxelles: Peter Lang, 2007.

MARTIN, D.; METZGER, J.-L.; PIERRE, P. Les métamorphoses du monde: sociologie de la mondialisation. Paris: Seuil, 2003.
MAUGERI, S. Au nom du client. Paris: L'Harmattan, 2006. METZGER, J. -L. La réforme permanente d'un service public: entre utopie et résignation. Paris: L'Harmattan, 2000.

. Elaboration et mode d'usage d'une typologie des collectifs. In: SAINT-LAURENT, A. -F. de; METZGER, J. -L. Où va le travail à l'ère du numérique. Paris: Editions de l'Ecole des Mines, 2007a. p. 23-50.

. La volonté de changer: l'institution du travail au risque du changement technico-organisationnel permanen. 2007b. $293 \mathrm{f}$. Thèse (pour l'obtention de l'habilitation à diriger des recherches)-Université d'Evry, Evry, 2007b. Disponível em: < http://tel. archives-ouverts.fr/tel-00455256/fr/> . Acesso em: 11 mar. 2011.

METZGER, J.-L.; CLEACH, O. Le télétravail des cadres: entre suractivité et apprentissage de nouvelles temporalités. Sociologie du Travail, v. 46, n. 3, p. 433-450, déc. 2004.

MOLINIÉ, A.-F. Les salariés quinquagénaires, entre fragilisation et protection. Retraite et Société, n. 49, p. 11-37. 2006.

NAVILLE, P. Vers l'automatisme social ? Problèmes du travail et de l'automation. Paris: Gallimard, 1963.

POMMIER, J.-L. et al. Ce salarié devrait cesser de travailler: une approche de l'usure professionnelle des 50 ans et plus. Retraite et Société, n. 49, p. 39-59, 2006.

REICH, Robert. L'Economie mondialisée. Paris: Dunod, 1993.

VALENDUC, G. La fracture numérique passe-telle par le travail? In: LELONG, B.; GRANJON, F.;. METZGER, J.-L. Inégalités numériques, clivages sociaux et modes d'appropriation des TIC. Paris: Hermès-Lavoisier, p. 137-159. 2009.

VALEYRE, A. Les conditions de travail des salariés dans l'Union européenne à quinze selon les formes d'organisation. Travail et Emploi, n. 112, p. 35-47, oct.-déc. 2007.

VENCO, S. Stratégies de gestion dans les centres d'appels brésiliens: omniprésence et visibilité. Recherches Sociologiques et Anthropologiques, n. 2, p. 55-76, 2009.

VOGEL, L. Enjeux et incertitudes de la politique européenne en santé au travail. Mouvements, v. 58, n. 2, p. 104-116, 2009. 